\title{
Expectant and Nursing Academics: The Interview Experience of Moms in Political Science
}

Angela K. Lewis, University of Alabama at Birmingham for the Committee on the the Status of Women in the Profession

ABSTRACT The challenges that women in academia face are well documented. However, there is a dearth of research on the experiences of female academics particularly on job interviews as expectant or nursing mothers. This study sought to document the experiences of these women. Considering the grueling nature of the academic job interview, do expectant or nursing mothers ask for accommodations on the interview, and if so, how do departments respond to their request? We find that women refrain from job interviews as expectant mothers while others suggest using the "hidden pregnancy phenomenon." Nursing mothers had more positive experiences, although experiences were less than desirable. Based on the findings, we offer a list of recommendations to departments to help improve this critical step in starting a career in academe.

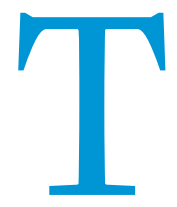

he challenges that women face in the academyand in political science-are well documented in studies that examine the pipeline, faculty recruitment, retention, publication rates, tenure, promotion, earnings, service responsibilities, and worklife balance (Ackelsberg et al. 2004; Assendelft et al. 2003; Brandes et al. 2001; Committee on the Status of Women 1992; Hesli and Burrell 1995; Mason and Goulden 2002; Sarkees and McGlen 1999; Stetson et al. 1990; Tolleson-Rinehart and Carroll 2006). Missing from the discussion, however, is the challenge of the interview process, a critical step for those in pursuit of an academic position and one that imposes some unique obstacles for women who are pregnant or nursing. This study is a first look at the challenges faced by mothers interviewing for positions in political science.

\section{MOTHERS WHO INTERVIEW}

Academic mothers are responsible to two uncooperative and "greedy institutions," the academy and the family (Coser 1974; Grant, Kennelly, and Ward 200o), each demanding undivided loyalty and commitment. The literature is replete with academic studies and reports about the challenges that women face in the academy (Ackelsberg et al. 2004; Assendelft et al. 2003; Brandes et al. 2001; Committee on the Status of Women 1992; Hesli and

Angela K. Lewis is associate professor in the department of government at the University of Alabama at Birmingham. She is the author of Conservatism in the Black Community: To the Right and Misunderstood. She has served on the APSA Committee on the Status of Women in the Profession and on the APSA Committee on the Status of Blacks in the Profession. She can be reached at dralewis@uab.edu
Burrell 1995; Mason and Goulden 2002; Sarkees and McGlen 1999; Stetson et al. 1990; Tolleson-Rinehart and Carroll 2006), but the collision between the two is perhaps most notable and noticeable in the interview process, one of the most important, necessary, and stressful first steps in an academic career. In principle, candidates and departments size each other up as they look for the best fit. In practice-particularly with crowded fields of applicantsthe burden is on candidates who must be adequately prepared mentally and physically for the interview. In this often first faceto-face contact the interview is a test of the candidate's endurance and stamina for at least one very long day, during which time she may meet with every faculty member of a department, undergraduate and graduate students, and a dean and provost (Gould and Keeter 2003); give a research presentation; and teach an undergraduate class (Carter and Scott 1998). The day(s) are packed with little or no free time and extend well into the evenings (Gould and Keeter 2003). And, there is often an extensive amount of time on one's feet during presentations, classes, and tours of campus.

The schedule can be grueling for anyone, but is a particular challenge for those who have difficulty standing or walking for long periods and distances, and who need frequent and regular breaks to attend to personal needs. Pregnant women and nursing mothers are among this group. In contrast to the other stages/ steps of the professional trajectory of female academics, we know little about how women experience this initial, critical step in the process of becoming a faculty member. Perhaps the most revealing discussion about pregnancy and women in the academy is by Armenti (2004), who coined the phrase "hidden pregnancy phenomenon" to describe the behavior of hiding maternal desires to 
manage the unwritten professional standards in the academy. Linking the past to the present, Armenti suggests that women used to opt out of childbirth or attempt to schedule birth at the end of the academic year, usually in May because it marked the end of the school year. Scheduling a May birth would cause the least disruption to their teaching and research schedules and would pose less of a burden to their colleagues who would have the responsibility of covering their classes in their absence.

In contrast, women are now less likely to delay their pregnancies, and instead try to conceal their pregnancies from colleagues and employers at every stage of their professional development from graduate school, through interviews, and well into the faculty appointments (see also Wilson 1995). Remembering her grad school days, one full professor explained how she concealed her pregnancy from the very beginning. "I had it all very, very, planned out, because in those days there wasn't any such thing as maternity leave" (Armenti 2001, 217). She switched her clothes from day to day, sometimes wearing them tight and other days loose so that by the time she was showing no one noticed that she was wearing large clothing. In her view, concealing her pregnancy might have been the difference between being employed and unemployed.

Similarly, Armenti's research includes a story by a now-assistant professor who also hid her pregnancy while on the job market. In her words, "It was just at that five-month stage where I could still get away with not ... revealing that I was pregnant, but it took a lot of work.... I think it [getting the job] would have been more difficult. I mean ... I think they would not have believed that I was going to finish my dissertation; they would never have believed that" (Armenti 2001, 220).

The utilization of the hidden pregnancy phenomenon expressed in these accounts may have been a wise strategy. For example, research by Cunningham and Macan (2007) demonstrates a pregnancy effect on interviewer ratings of job candidates who were recent graduates of midwestern business schools who applied for computer programmer positions. They found that despite being rated as equally qualified and fit for the job as their competitors, "the pregnant applicant received significantly lower hiring recommendations from both male and female raters (504, italics added)." In contrast, earlier work by Gueutal, Luciano, and Michaels (1995) found that pregnancy had a positive impact on appraisal ratings for women employees, attributable to one of two factors: either women over-performing to mitigate concerns from colleagues, or to leniency on the part of the supervisor, or both.

Women who are nursing have different challenges than pregnant women. Although it may be easier to conceal whether one is nursing, there are challenges associated with nursing needs-in particular, expressing milk-that may be exaggerated in an interview setting. For many women, nursing their baby is not a choice but a critical part of both pediatric and maternal health (see American Academy of Pediatrics 1997; US Department of Health and Human Services 2011). Yet, despite the Patient Protection and Affordable Care Act's (PPACA) requirement that employers provide break times and a suitable location in the workplace for milk expression, women continue to report having to raise the issue with (potential) employers and colleagues. Moreover, women also describe difficulties with managing the work environment to express milk. A poignant example from a job candidate writing at the Chronicle of Higher Education's Academic Job Forum, an online discussion forum on the job search in higher education, illus- trates how little progress has been made in the academy. The mother of a breast-feeding seven-month-old baby who was ready to interview on multiple campuses over a several week stretch expressed concern that despite the constant pumping she was doing in advance of her absence to store milk for her child, she would still have to pump during her interviews. Not sanguine about having to share too much personal information in a professional setting, she wondered how to approach search committees with a request for time to express milk. Every response to her post suggested that she not ask for breaks, one suggested she wean the baby before interviewing, and another suggested that she take her pump but be very discrete about it (16)." Another woman explains that despite her efforts to pump in advance, during a four-day interview trip away from her six-month-old, her supply dried up and she was unable to continue nursing her child.

Given the stressfulness of an academic job interviewparticularly the formal presentation that tends to be confrontational and adversarial and a test of character and collegiality (Hassner 2008) - it is reasonable to wonder how a nursing mother who has not had an opportunity to express milk can stay effectively focused and attentive to others in this setting.

Thus, what are the experiences of expectant and nursing mothers in the political science interview process? The APSA Committee on the Status of Women in the Profession (CSWP) sought to document the interviewing experiences of expectant or nursing women faculty. This article documents the interviewing experiences of female political scientists and suggests some best practices that could benefit all job candidates.

\section{STUDYING POLITICAL SCIENCE MOTHERS ON THE MARKET}

This study captures the experiences of female political science faculty on the market and shares their stories as a first step toward thinking about best practices for interviewing in political science. Female political scientists were invited to participate in an online survey by e-mail using member lists provided by APSA $^{1}$ and by announcement by the Committee on the Status of Women in the Profession (CWSP) in PS: Political Science and Politics and at the 2010 APSA Annual Meeting. Three hundred and forty-nine women responded to the call. The majority who identified their race were Caucasian (269, 87.6\%); Asian American women constituted 5.9\% (18) of respondents, African American women 4.2\% (13), Latinas 1.6\% (5) and American Indians .7\% (2). Three-quarters of the respondents who identified their age were $30-49$ years old (235, $75.5 \%$ ); women under 30 were $5.8 \%$ (18) of respondents and women 50 and over were $28.6 \%$ (58) of respondents.

The survey instrument asked forced-response and open-ended questions about women's interview experiences when pregnant and/or nursing. ${ }^{2}$ Nearly a quarter of the female political scientists in our study indicated that they delayed their decision to become pregnant to go on the market $(66,23 \%)$, and fewer responded that they were pregnant during their interview $(s)(52,14.9 \%)$. Nursing seems to have been less important in the job market calculus than pregnancy, with only $4.2 \%(n=12)$ of the respondents indicating they delayed the decision to go on the market because they were nursing $(12,4.2 \%)$; nearly three times as many $(40,11.8 \%)$ nursed at the time of their interview(s).

Although these data may suggest interesting divergences in the role that motherhood plays in this particular stage of a female academic's career, the small number of respondents in this study limits our ability to draw general conclusions about 
the experiences of women interviewing for political science positions. However, the anecdotal stories shared by many of the respondents about their interview experiences provides some basis for further study and preliminary reflections about how the interview process works for pregnant and nursing women in political science. $^{3}$

\section{EXPERIENCES OF INTERVIEWING MOTHERS}

\section{Expectant Moms}

The expectant women in this study offered interesting insights into the job market and interview process in political science. Many of these are negative and mirror the concerns that others have found in their research, including hiding pregnancy from interviewers and delaying pregnancy to avoid problems during the market and interview process. Yet some are positive, suggesting there may be progress in the ways that mothers-to-be are treated in the political science interview process.

For some, the most notable feature of interviewing while pregnant was how difficult it was physically. One respondent said, "If at all possible, I would avoid interviewing while pregnant. It was extremely tiring and difficult, and the concerted stress cannot possibly be good for the pregnancy." Another recommended, "Try to avoid when possible! Simply too exhausting." And another pregnant interviewer went on only one interview while pregnant and then cancelled the others, "because the interview process was so exhausting. I wasn't sure I could make it through another 2-day gruel."

For other respondents, the experience demonstrated bias against expectant mothers. One woman informed her potential interviewers that she was pregnant in advance of the interview, and, "They encouraged me to come, but when I arrived, I sensed that the department was divided and that no offers would be made, which turned out to be correct. After that, I quit interviewing while pregnant." Another respondent who was six months pregnant at the time of her interview shared, "At one [interview], I was made to feel uncomfortable," and the "first question in our private interview was, "Well, what would your husband do if you got the job?" This respondent also stated how a female faculty member was shocked to see her belly. This same respondent did have more positive experiences at other interviews, but in the end, her recommendation to others was, "The best way to interview is nonpregnant and ringless. Honestly, I finally got a good job, plus a spousal accommodation, when I kept everything a secret during the interview process: my kids and my spouse."

This type of bias was not only evident from men, but women as well. "I realized that there was a blatant bias against expectant faculty, particularly from older male faculty, and tenured female faculty." Another respondent provided greater detail about her experience. After hiding her pregnancy and then negotiating start date around the baby's birth, "He [the chair] grudgingly agreed to a ... start date and the vibe was awful when I did finally arrive. Everyone was cold to me (even the women). It took me years of publishing and generous collegial behavior before I won these people over. And that goes for the women on the faculty, too." This respondent sensed that the university wanted to send a message to women faculty to wait for tenure to have a baby.

Several women on the market hid their pregnancy during their interviews for fear that it would be used against them. As one respondent said, "It is very difficult to interview while pregnant. I would not choose to go on the job market visibly pregnant. I did not disclose my pregnancy during my job interviews; it would have been a liability. It was my impression that departments were interested to know whether you were at the beginning of family life-or had finished having children." Another explained,

When I interviewed the first time, pregnant, the worries that had led me to keep it a secret were confirmed. I was asked about my family life by three different faculty members. I was deeply uncomfortable with the entire interview. Further, I doubted my own abilities-I was exhausted throughout the interview, given the stage of the pregnancy; uncomfortable because I could not enjoy a glass of wine at dinner, and could not tell anyone why I would not drink. I could not imagine telling them why I was so tired, and why I could not drink. The entire situation was miserable.

Other women reported delaying pregnancy until after they interviewed for academic positions. Typical of these responses were: "Being an academic usually means delaying pregnancy one way or another," "It didn't occur to me to try to start a family before I had a tenure-track job. I ended up not getting pregnant until after I was tenured," and, "I delayed having children until I was solidly established in an academic job." Others indicated, "I never even considered trying to have a child before I had completed my $\mathrm{PhD}$ and secured a job. I don't think I would have been able to finish the $\mathrm{PhD}$ and be on the market if we had had children. The cost of care and health insurance would have been too high to cover with fellowships/TA funds" and "I specifically timed my job search and employment to coordinate with our family plans." Although these women waited to have a child until after interviewing and receiving a job offer, others did not and had positive experiences. Although this respondent did not know she was pregnant at the time of the interview, she knew when she was offered the job, stating "When my offer was extended, I knew and was treated fairly." And lastly, another respondent in reference to a job opening stated, "It actually never crossed my mind not to seek the job because I was pregnant. The dean, when he found out I was pregnant, was supportive and accommodating as were all my colleagues."

\section{Nursing Mothers}

Overall, the experience of nursing mothers seemed more positive than expectant mothers. Although respondents did not intentionally hide the fact that they were nursing mothers, many implied that they did not bring it up. In fact, one respondent stated, "Hid the fact from interviewers, but secretarial support staff were very helpful." Other respondents stated that they had informed the department that they had a newborn and that they asked for extra breaks and were granted them. Some nursing mothers also had their infants accompany them on the interview so they could continue to nurse despite the interview. Another respondent asked for childcare during the interview.

Most of the requests for accommodations were for extra breaks and a private room to pump. A few respondents asked for specific time breaks of every three or four hours. And another who did not ask for accommodations from the institution had a one day interview split into two days so she could pump.

There were some negative experiences for nursing moms however. Two different respondents stated:

I did not ask for accommodations because I did not want to bring up the fact that I had a new baby and needed accommodations. In 
retrospect this was a mistake because I did not have time to pump, which was distracting, uncomfortable, and also I ended up leaking during my job talk (but fortunately only I knew this). It was very difficult.

A second stated, accommodations given for time, but no room or place offered to feed. I remember having to sit in toilet stall to feed. Awkward and did not feel welcoming.

Another stated,

Time for pumping was provided, but it required many uncomfortable discussions with many people who did not need to ask about it. I continue to interview for academic positions. I plan to apply for positions next job-market season if I do not obtain one this year. I would also note that the degree of perceived faculty "comfort" with my status as a nursing mother varied within and across institutions. Some faculty members, mainly women and men with young children, seemed perfectly comfortable. In other cases, it was more awkward. For example, I was asked once by a female to take steps to hide the pumping from certain faculty members so as not to make them uncomfortable. A man at another institution asked me how "pumping works" and then appeared quite embarrassed. Of course, this variation is to be expected, but it was a constant concern for me on my interviews. So obvious a signal that I was a mother also opened me up to many questions about my children, family, and plans to balance career and family. It seemed that being open with the fact that I was a nursing mother made people much more comfortable asking me personal questions in general. Though many of these questions were asked with what I assume to be the best of intentions, they resulted in more attention to nonprofessional matters during limited interview time. At times, they bordered on inappropriate: for example, during one dinner with three senior male faculty members, I was asked whether I had had my children "naturally." It was clearly intended as small talk and asked without much thought, but it clearly would never be asked of my male competition!

The need for nursing mother's to express milk during the interview process is distracting. Nursing mothers often have to choose between expressing milk or being late for a scheduled appointment. Because the interview schedule is often packed with backto-back meetings with little time for even restroom breaks, nursing mothers may end up being in very difficult situations if they do not ask for accommodations. For example,

At all interviews I did receive the use of a private room and there were attempts made to create adequate breaks in my schedule. However, at all interviews, in practice, I ended up having to either skip at least one scheduled pumping. In most cases this was because the room provided was far from scheduled meetings, and time was not included for travel. In some cases, meetings and interviews ran over the allotted time. In these cases I found myself choosing to skip the pumping rather than arrive late for appointments or request additional accommodations. In two interviews I was asked to use the time on the schedule immediately prior to my job talk to pump and told I could "prepare while pumping." In one case, I missed a flight home because the day's interviews ran late and I simply had to pump before flying-I had already pushed time between pumpings to the limit.

\section{RECOMMENDATIONS}

From the study, it appears there is room for improvement in the way political scientists treats expectant and nursing mothers on job interviews. Although as a field, political science has accom- plished a great deal in gender equity, much work remains. For example, many respondents had a variety of things to say about underlying bias and perceptions concerning academic mothers among both male and female faculty, bias in the way female caregivers are treated versus how male caregivers are treated, how women are told that they cannot have children and be academics, and differences in salaries between male and female faculty. Others suggested that we focus on interview tips for graduate students like their appearance on an interview and whether to reveal that they may have interests in researching gender and sexuality. And finally, more advanced scholars complained that women are more often queried about their families than men. We recognize that there is a good deal of progress yet to be made concerning women in the academy, but our primary objective was to get information about the experiences of expectant and nursing mothers during the very important first step to entering the academy: the academic job interview. Although the academic job interview vets potential colleagues, candidates also interview departments. For departments to make the best first impression, a good starting point is to always offer accommodations for candidates or at least have the possibility of breaks built into the schedule. As one respondent noted, this offer would not be limited to women but to all candidates. They stated:

Now that I am in a position to hire faculty, I always ask about accommodations we can make, or information we can gather, for interviewees-not just mothers, but persons with disabilities, persons with partners who might be looking for work, people with older children who might go to school in the area.

The academic job interview is an important step in a professor's career. Based on the survey results, we have compiled a list of recommendations for institutions and the profession. Some suggestions will benefit all job candidates, while others focus on improving the overall atmosphere for families. To advance our discipline and for the benefit of all job candidates we offer these recommendations:

1. Provide everyone involved in the interview process a list of appropriate and inappropriate interview questions as well as information regarding the Pregnancy Discrimination Act (1978) which requires that employers treat pregnant employees the same as other employees with temporary disabilities or limitations (Cunningham and Macan 2007). Those involved in the interview process should also be made aware of Section 7 (r) of the Fair Labor Standards Act that contains provisions for nursing mothers. The law requires employers to provide reasonable break times for nursing mothers and places for mothers to express milk other than a bathroom that is free from intrusion.

2. When inviting the candidate for the interview, be open and accommodating and give the candidate an idea about what type of schedule they will have for the interview. They should also be informed of other logistical issues like the amount of walking and the weather of the local area.

3. Provide at least one meal time a day where the candidate can be alone.

4. Provide at least two $15^{-20}$ minute breaks in a private place between meetings and presentations. If the interview last more than eight hours, provide the candidate with at least 
one thirty-minute break. Stay on the schedule and ensure the candidate takes the breaks provided.

5. If possible, consider transporting candidates by car around campus or using the campus shuttle to limit walking long distances.

6. If the candidate asks for accommodations, keep the information in confidence. Only the department chair or chair of the search committee should know about the request.

7. Be sensitive to the candidate's diet including whether they decide to drink alcoholic beverages.

8. Provide local information to all candidates about child-care facilities on and off campus and local schools. However, refrain from asking whether the candidate has children.

9. Incorporate interview training in APSA's chairs workshop.

10. Incorporate career and family workshops at annual meetings for graduate students and faculty. These workshops could focus on strategies for dealing with personal questions on interviews and success stories for female graduate students to help mitigate the idea that it is impossible to have children and be a successful professor.

11. Institutionalize support for faculty with children by offering flexible schedules, tenure extensions, paid maternity leave, and child-care options.

\section{CONCLUSIONS}

The academy has certainly made strides in the development of family-friendly policies but more work remains. Although the research presented here focuses exclusively on the interview process, the CSWP understands that a variety of additional issues in women's careers need to be addressed. However, we were made aware of the treatment of expectant and nursing mothers while interviewing, and there is a dearth of research in political science on the interview process. Therefore, we believed that it was important to begin to address how women are treated during the interview process. If women are unsuccessful during the interview process or are treated with bias, how far have we really come? Future research should continue to unravel the many intricacies involved in women navigating the academy. For now making the interview process more comfortable for all job candidates is a step in the right direction.

\section{ACKNOWLEDGMENTS}

The author thanks numerous individuals for their assistance in this report including, former CSWP members Barbara Burrell, Gretchen Casper, Paula McClain, Kristen Renwick Monroe, Joanna Vecchiarelli Scott, and Valerie Sperling. The author also thanks Clarissa Peterson for her assistance with the survey instrument and Jennifer Diascro for her assistance in improving the manuscript. $~-~$

\section{NOTES}

1. $N=4,102$.

2. Please see the appendix for survey instrument.

3. This method is similar to the method utilized by Connelly and Ghodsee 2011.

\section{REFERENCES}

The Academic Job Forum. 2004. Chronicle of Higher Education 51 (16) (C4). http:// search.ebscohost.com $/$ login.aspx?direct $=$ true $\& \mathrm{db}=\mathrm{aph} \& \mathrm{AN}=15540234=$ ehost-live (Accessed August 25, 2011).
Ackelsberg, Martha, Gayle Binion, Georgia Duerst-Lahti, Jane Junn, Laura Assendelft, and Bang-Soon Yoon. 2004. "Remembering the 'Life' in Academic Life: Finding a Balance Between Work and Personal Responsibilities in the Academy." PS: Political Science and Politics 37 (4) (October): 879-83.

American Academy of Pediatrics. 1997. "Breastfeeding and the Use of Human Milk." Pediatrics 100: 1035-39.

Armenti, Carmen. 2001. "May Babies and Posttenure Babies: Maternal Decisions of Women Professors." The Review of Higher Education 27 (2): 211-31.

_ 2004. "May Babies and Posttenure Babies: Maternal Decisions of Women Professors." Review of Higher Education 27 (2): 211. http://search.proquest.com/ docview/220846101 ?accounid $=8240$.

Assendelft, Laura, Wendy Gunther-Canada, and Julie Dolan. 2001. "The Status of Women in Political Science Departments in the South: Results of the Millennium Survey." PS: Political Science and Politics 34 (2): 333-38.

Assendelft, Laura, Wendy Gunther-Canada, Julie Dolan, Barbara Palmer, and Michele Swers. 2003. "Political Science in a Different Voice: Women Faculty Perspectives on the Status of Women in Political Science Departments in the South." PS: Political Science \& Politics 36 (2): 311-15.

Brandes, Lisa, Eloise Buker, Susan Burgess, Constance Cook, Janet Flammang, Shirley Geiger, Susan Okin, Bank-Soon Yoon, and Martha Ackelsberg. 2001. "The Status of Women in Political Science: Female Participation in the Professoriate and the Study of Women and Politics in the Discipline." PS: Political Science and Politics 34 (2): 319-26.

Carter, Ralph G., and James M. Scott. 1998. "Navigating the Academic Job Market Minefield." PS: Political Science and Politics 31 (3): 615-22.

Centers for Disease Control and Prevention. 2011. Breastfeeding: Travel Recommendations for the Nursing Mother. April 21. http://www.cdc.gov/breastfeeding/ recommendations/travel_recommendations.htm (Accessed May 30, 2011).

Committee on the Status of Women. 1992. "Improving the Status of Women in Political Science: A Report with Recommendations." PS: Political Science and Politics 25 (3): 547-54.

Connelly, Rachel, and Kristen Rogheh Ghodsee. 2011. Professor Mommy: Finding Work-Family Balance in Academia. Lanham, MD: Rowman \& Littlefield Publishers.

Coser, Lewis A. 1974. Greedy Institutions: Patterns of Undivided Commitment. New York: Free Press.

Cunningham, Jennifer, and Therese Macan. 2007. "Effects of Applicant Pregnancy on Hiring Decisions and Interview Ratings." Sex Roles: A Journal of Research 57 (7-8): 497-508.

Gould, Jon B., and Scott Keeter. 2003. "No Second Chance at Making a Good First Impression: Peril and Possibility in the Campus Visit." PS: Political Science and Politics 36 (4): 791-94.

Grant, Linda, Ivy Kennelly, and Kathryn B. Ward. 200o. "Revisiting the Gender, Marriage, and Parenthood Puzzle in Scientific Careers." Women Studies Quarterly 28 (1-2): $62-85$.

Gueutal, Hal G., Joan Luciano, and Carole A. Michaels. 1995. "Pregnancy in the Workplace: Does Pregnancy Affect Performance Appraisal Ratings?" Journal of Business and Psychology 10 (2): 115-67.

Hassner, Ron E. 2008. “Trial by Fire: Surviving the Job Talk Q\&A." PS: Poltical Science and Politics 41 (4): 803-08.

Hesli, Vicki, and Barbara Burrell. 1995. "Faculty Rank Among Political Scientists and Reports on the Academic Environment: The Differential Impact of Gender on Observed Patterns." PS: Poltical Science and Politics 28 (1): 101-11.

Mason, Mary Ann, and Marc Goulden. 2002. "Do Babies Matter? The Effect of Family Formation on the Lifelong Careers of Academic Men and Women." Academe (American Association of University Professors) 88 (6): 21-27.

Sarkees, Meredith Reid, and Nancy E. McGlen. 1999. "Misdirected Backlash: The Evolving Nature of Academia and the Status of Women in Poltical Science." PS: Political Science and Politics 32 (1): 100-08.

Stetson, Dorothy McBride, Diane Wall, Diane Blair, Mary Ellen Guy, Erika Fairchild, David Canon, and Cheryl Brown. 1990. "The Status of Women in Ph. D. Departments." PS: Political Science and Politics 23 (1): 82-86.

Tolleson-Rinehart, Sue, and Susan J. Carroll. 2006. "Far from Ideal': The Gender Politics of Political Science." The American Political Science Review 100 (4): 507-13.

US Department of Health and Human Services, Office of the Surgeon General. 2011. The Surgeon General's Call to Action to Support Breastfeeding. Washington, DC: Department of Health and Human Services. http://www.surgeongeneral. gov/library/calls/breastfeeding/calltoactiontosupportbreastfeeding.pdf

US Department of Labor, Wage and Hour Division. 2010. Fact Sheet \#73: Break Time for Nursing Mothers under the FLSA. Washington, DC: Department of Labor. http://www.dol.gov/whd/regs/compliance/whdfs73.pdf.

Wilson, Robin. 1995. "Scheduling Motherhood." The Chronical of Higher Education 40 (26): $14-15$. 


\section{APPENDIX: Survey Instrument}

When you interviewed for academic jobs, were you pregnant/nursing mother?

How many interviews did you go on as an expectant mother/nursing mother?

Did you try to hide your pregnancy/the fact that you were a nursing mother?

Was your pregnancy apparent to the interviewers?

What year was this interview?

At the time of this interview, approximately how many years of teaching experience did you have?

What was the level of the position for which you were interviewing?

Was this your first interview on the academic job market?

What type of institution provided you with this interview?

In what state was this institution located?

How many faculty members did the institution have in the department for which you interviewed?

How many female faculty did the institution have in the department for which you interviewed?

What were the ranks of the female faculty within the department? How many female faculty members were within the ranks below?

Did you ask for accommodations?

Please list the accommodations (i.e. private rooms, extra breaks between meetings, less walking, special seating) provided by the institution during your interview. If you did not receive any accommodations, please put none.

Were you offered a position at this institution?

Did you accept the position?

Did any of your experiences while interviewing as a/an expectant mother/nursing mother influence your decision to continue interviewing?

Did you delay your decision to go on the job market because you were pregnant/a nursing mother?

Did you delay your decision to become pregnant because you were planning to go on the job market?

Have you ever received advise from any of those listed below that you should not interview while you are pregnant/nursing mother?

What is your age?

What is your race? 